\title{
The attitudes and behaviors of students, staff and faculty towards smoke-free and tobacco-free campus policies in North American universities: A narrative review
}

\author{
Daniel Dilliott', Sajjad Fazel1,2, Nazia Ehsan', Shannon L. Sibbald ${ }^{1,3}$
}

\begin{abstract}
INTRODUCTION In Canada, a series of recent public health policies and interventions have successfully led to a decline in national tobacco use rates. However, tobacco use among young adults remains high and the tobacco industry continues to place a strong marketing emphasis towards young adults on university campuses. In response, many universities across Canada are beginning to adopt smoke-free or tobacco-free campus policies. While the effectiveness of smoke-free and tobaccofree campus policies has been demonstrated in several countries, little is known about the attitudinal responses of university students, faculty and staff towards these policies. As such, we conducted a review of the literature to summarize the findings of studies conducted in North America regarding the attitudes and beliefs of campus community members towards smoke-free or tobacco-free campus policies.

METHODS Using a pre-defined search strategy and Boolean string, we searched three databases for published articles pertaining to the research question. Only primary and peer-reviewed articles of studies conducted on North American university campuses were eligible for inclusion. Studies included for review were those published in English within the last five years. All studies included in the review contained outcome measurements related to the attitudes and behaviors of faculty, staff and students towards smoke-free and/or tobacco-free campus policies.

RESULTS A total of 11 articles were included for analysis and result synthesis. Recent research indicates that individuals' attitudes and beliefs towards smoke-free or tobacco-free campus policies are influenced by social norms, smoking status, secondhand smoke exposure, and sociodemographics.

CONCLUSIONS This literature review provides timely information for universities in the process of developing or implementing a smoke-free campus policy. The attitudes and beliefs of university students, faculty and staff can determine success and compliance to newly implemented smoke-free campus policies.
\end{abstract}

\section{AFFILIATION \\ 1 The Schulich Interfaculty Program in Public Health, Schulich School of Medicine and Dentistry, Western University, London, Canada 2 Cancer Epidemiology and Prevention Research, Alberta Health Services, Calgary, Canada 3 Department of Family Medicine, School of Health Studies, Faculty of Health Sciences, Schulich School of Medicine and Dentistry, Western University, London, Canada}

\section{CORRESPONDENCE TO}

Sajjad Fazel. Cancer Epidemiology and Prevention Research, Alberta Health Services, Holy Cross Centre, 2210-2St. SW, Calgary, AB T2S 3C3, Canada. E-mail: sfazel3@uwo.ca ORCID ID: https://orcid.org/00000002-6457-4017

\section{KEYWORDS}

attitudes, North America, smokefree, tobacco-free, University, policy

Received: 9 June 2020 Revised: 5 July 2020

Accepted: 8 July 2020

\section{INTRODUCTION}

Despite recent decreases in national smoking rates due to several successful public health interventions, diseases related to tobacco use remain among the leading causes of premature morbidity and mortality in Canada ${ }^{1}$. Tobacco consumption has been shown to be more prevalent among Canadians aged 18-
34 years $^{2}$, which reveals a target group for health promotion initiatives aiming to reduce further usage of commercial tobacco products ${ }^{3,4}$. Recent statistics indicate that $74.7 \%$ of Canadians attend postsecondary institutions, providing an opportune setting for implementing tobacco-related health promotion proposals ${ }^{5}$. Universities have a large number of 
employees, who can be additional targets for campus initiatives that aim to reduce tobacco use ${ }^{6}$.

However, the university campus environment has unique challenges when implementing programs and policies to reduce tobacco use ${ }^{7}$. Despite recent progress in combating the tobacco industry's influence on campus, as of 2005 tobacco industries have had a strong marketing presence among most Canadian universities and colleges by providing donations and sponsoring promotional events ${ }^{8}$. For example, between 1996-1999 tobacco companies made donations to $39 \%$ of Canadian universities 9 . Evidence also suggests that between 19962001, several Canadian universities had tobacco industry officers holding appointments with their institutions 9 . Campus tobacco policies have also generally been met with protest from members of the campus community ${ }^{10}$. For a tobacco-reducing health promotion strategy to be successful, these challenges, among others, need to be considered ${ }^{7,8,10}$.

Public smoking bans have been largely successful at breaking the smoking habits of Canadians and have contributed to an observable decrease in the national percentages of smokers since $2000^{11,12}$. The effectiveness of campus-wide smoking and tobacco bans, which encompass all indoor and outdoor spaces of a post-secondary institution, have also been well documented in literature from the United States and the United Kingdom ${ }^{13,14}$. Only a handful of Canadian universities have instituted smoking bans ${ }^{15}$. Despite the success of North American smoke-free and tobacco-free campus initiatives, there remains a gap in understanding the attitudinal and behavioral factors that may influence compliance with these policies ${ }^{13,14}$. Given the lack of Canadian data, the aim of this literature review is to provide an overview of the attitudes and behaviors of university students, staff and faculty towards smoke-free and tobaccofree campus initiatives in North America.

\section{METHODS}

\section{Search strategy}

The following databases were searched for published articles: PubMed, Web of Science and PsycInfo. These three databases were selected because they primarily contain articles covering subject areas relevant to the topic being investigated: biomedical sciences, healthcare sciences, and social behavior.
While searching for sources, these regularly updated databases returned peer-reviewed articles published in key Tobacco Control journals. Three reviewers searched the three databases with the following Boolean string: [(attitude OR behavior) AND (smoke-free OR tobacco-free) AND (campus OR university) AND (North America OR USA OR United States OR Canada OR Mexico)]. Three researchers independently examined the abstracts and full text of articles based on the pre-defined inclusion and exclusion criteria. Discrepancies were resolved through a consensus discussion with all researchers.

\section{Inclusion and exclusion criteria}

Eligibility criteria were defined prior to the database search in order to only include studies that were relevant to the research question. The search was set to return articles published within the last five years and written in English. Only primary and peerreviewed articles of studies conducted in North American university campuses were included. The outcome measurements of included studies were related to the attitudes and behaviors of faculty, staff and students towards smoke-free and/or tobaccofree campus initiatives, this includes policies that may have additional restrictions such as hookah and waterpipe smoking. Studies that examined attitudes towards electronic cigarette and/or tobacco chewing bans alone were excluded. In addition, studies that focused on measuring the effectiveness of intervention or policy as the main outcome were excluded. Eligibility for inclusion in the literature review was first independently assessed by three reviewers through screening of titles and abstracts. The three reviewers subsequently reviewed the full text of articles considered to be eligible for inclusion after title and abstract screening. Any disagreements between the reviewers regarding article inclusion were resolved through discussion. The inclusion and exclusion criteria are further illustrated in Figure 1.

\section{RESULTS}

A literature search of PubMed yielded 417 results, Web of Science 25 results, and PsycInfo yielded 65 results. The search of the three databases returned 497 articles, of which 471 were excluded after title and abstract screening. Of the 26 articles included after title and abstract screening, three duplicates 
Figure 1. Flow diagram of article selection
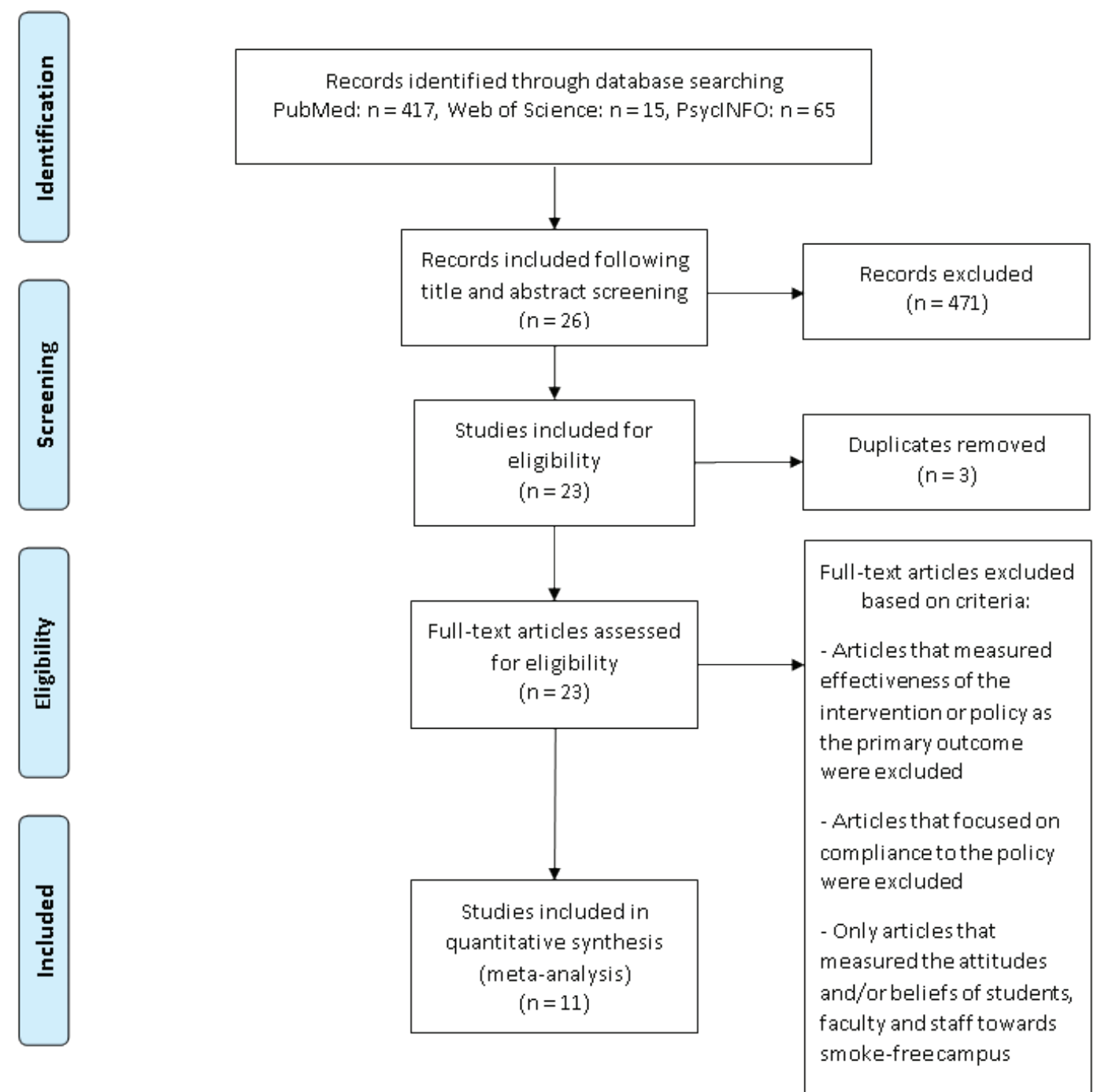

were removed. The full text of the 23 remaining articles were subsequently assessed for inclusion eligibility using the predetermined set of eligibility criteria. Twelve articles were removed after eligibility assessment and the remaining 11 articles were included for analysis and result synthesis. The characteristics of the included studies are illustrated in Table 1.

\section{Table 1. Characteristics of studies included in review}

\begin{tabular}{|c|c|c|c|}
\hline Study & Country & Participants & Measures \\
\hline $\begin{array}{l}\text { Fallin et al. }{ }^{24} \\
\text { (2013) }\end{array}$ & United States & 1309 college students & $\begin{array}{l}\text { Secondhand smoke exposure, intention to smoke on campus, and } \\
\text { support for outdoor smoking restrictions. }\end{array}$ \\
\hline $\begin{array}{l}\text { Procter-Scherdtel } \\
\text { and Collins }{ }^{17} \\
(2013)\end{array}$ & Canada & 36 key participants & $\begin{array}{l}\text { Key participant interviews to measure perspectives on institutional } \\
\text { and population norms. }\end{array}$ \\
\hline $\begin{array}{l}\text { Wallar et al. }{ }^{19} \\
(2013)\end{array}$ & Canada & $\begin{array}{l}490 \text { individuals ( } 61 \% \\
\text { undergraduate students, } 16 \% \\
\text { staff, } 13 \% \text { graduate students, } \\
4 \% \text { faculty members) }\end{array}$ & $\begin{array}{l}\text { Secondhand smoke exposure, tobacco use, self-identified tobacco } \\
\text { user status, knowledge of tobacco-related programs and policies, } \\
\text { opinion on } 7 \text { different tobacco policy options, attitude towards a } \\
\text { 100\% smoke-free campus and basic demographics. }\end{array}$ \\
\hline
\end{tabular}


Table 1. Continued

\begin{tabular}{|c|c|c|c|}
\hline Study & Country & Participants & Measures \\
\hline $\begin{array}{l}\text { Seitz and Strack }{ }^{10} \\
\text { (2014) }\end{array}$ & United States & $\begin{array}{l}\text { News reports covering } \\
21 \text { protests over newly } \\
\text { implemented or proposed } \\
\text { policies on college campuses }\end{array}$ & $\begin{array}{l}\text { Historical analysis of historical documents using theory of triadic } \\
\text { influence framework. }\end{array}$ \\
\hline $\begin{array}{l}\text { Braverman et } \\
\text { al. }^{18}(2015)\end{array}$ & United States & $\begin{array}{l}5691 \text { students and } 2051 \\
\text { faculty/staff }\end{array}$ & $\begin{array}{l}\text { Support for a smoke-free campus, smoking status, exposure to } \\
\text { secondhand smoke and perceptions of levels of policy support and } \\
\text { campus smoking. }\end{array}$ \\
\hline $\begin{array}{l}\text { Hall et al. }{ }^{22} \\
(2015)\end{array}$ & United States & $\begin{array}{l}265 \text { students, } 138 \text { staff and } \\
44 \text { faculty }\end{array}$ & $\begin{array}{l}\text { Demographics, campus role, policy acceptance, smoking status, } \\
\text { degree of agreement to issues related to campus tobacco policies } \\
\text { and secondhand smoke. }\end{array}$ \\
\hline $\begin{array}{l}\text { Cooper et al. }{ }^{20} \\
(2016)\end{array}$ & United States & $\begin{array}{l}3002 \text { faculty, students and } \\
\text { staff }\end{array}$ & $\begin{array}{l}\text { Attitudes towards tobacco-free campus policies, tobacco-use risk } \\
\text { perception and perceived problematic tobacco use. }\end{array}$ \\
\hline $\begin{array}{l}\text { Mamudu et al. }{ }^{25} \\
(2016)\end{array}$ & United States & 790 college tobacco users & $\begin{array}{l}\text { Support for tobacco-free policies and campuses and } \\
\text { sociodemographic-political characteristics. }\end{array}$ \\
\hline $\begin{array}{l}\text { Braverman et } \\
\text { al. }{ }^{21}(2017)\end{array}$ & United States & $\begin{array}{l}4138 \text { students and } 1582 \\
\text { faculty/staff }\end{array}$ & $\begin{array}{l}\text { Support for a smoke-free campus, opposition to a tobacco-free } \\
\text { campus, tobacco use, exposure to secondhand smoke on campus, } \\
\text { perceptions of smoking-related norms and demographic and campus } \\
\text { life variables. }\end{array}$ \\
\hline $\begin{array}{l}\text { Ickes et al. }{ }^{23} \\
(2017)\end{array}$ & United States & $\begin{array}{l}660 \text { undergraduate and } \\
\text { graduate students }\end{array}$ & $\begin{array}{l}\text { Demographic characteristics, secondhand smoke exposure and } \\
\text { tobacco use, beliefs about the tobacco-free campus policy. }\end{array}$ \\
\hline $\operatorname{Record}^{16}(2017)$ & United States & $\begin{array}{l}479 \text { undergraduate students } \\
\text { who had smoked at least } 100 \\
\text { cigarettes in their lifetime }\end{array}$ & $\begin{array}{l}\text { Attitudes toward tobacco-free policy compliance, subjective norms, } \\
\text { perceived behavioral control, behavioral intention and compliance } \\
\text { behaviors. }\end{array}$ \\
\hline
\end{tabular}

\section{DISCUSSION}

This literature review examined the findings of eleven studies that looked at the attitudes and behaviors of students, faculty and staff towards smoke-free and tobacco-free policies across university campuses in North America. There are several sociodemographic factors that can influence a person's attitude and behavior towards smoke-free and tobacco-free campus policies.

One of the studies from our review of the literature surveyed undergraduate students across universities in the southern United States regarding their compliance behaviors towards tobaccofree policies ${ }^{16}$. The study found that students' behaviors and attitudes towards smoke-free and tobacco-free campuses can be explained using the theory of planned behavior ${ }^{16}$. The theory of planned behavior model specifically explains the importance of attitudes, subjective norms, behavioral intention and control in determining compliance behaviors to smoke-free campuses ${ }^{16}$. The findings of Record ${ }^{16}$ suggest that addiction plays a major role in influencing behavior towards smoke-free and

tobacco-free campus policies. However, perceived attitudes, subjective norms and behavioral control were similarly found to influence individual behavior among undergraduate students across universities in the southern region of the United States ${ }^{16}$. In addition, the study showed that one's perception of social pressures and the perceived ability to comply with smoke-free initiatives are important indicators for compliance behaviors ${ }^{16}$.

\section{Social norms}

The importance of social norms influencing the attitudes and behaviors of students towards a smokefree campus is further emphasized by the findings of Procter-Scherdtel and Collins ${ }^{17}$. Changes in social norms due to newly-enacted smoke-free campus policies have been found to induce changes in students' behaviors; people tend to act in a way that is socially approved by their peers ${ }^{17,18}$. Among students attending universities with smoke-free policies across Canada, social consequences and sanctions that result from not complying with social norms were shown to cause individuals to shift towards a more 
socially acceptable behavior ${ }^{17}$. Some individuals who disagreed with smoke-free campus policies, but were required to abide by them, initially experienced a degree of psychological discomfort ${ }^{17}$. However, the findings of Procter-Scherdtel and Collins ${ }^{17}$ suggest that these individuals eventually changed their attitudes and behaviors to protect their self-esteem.

The attitudes of students towards smoke-free campus policies vary, with some students supporting the policies and others disagreeing with them ${ }^{17,19}$. A study conducted across three universities in Canada noted that students who have positive attitudes towards smoke-free policies see universities as role models that should promote the social disapproval of smoking ${ }^{17}$. In addition, it was found that the majority of university students across Canada and the United States accept smoke-free environments and understand that smoking bans can change behaviors ${ }^{17,20}$. Contrary to these findings, a survey of students, staff and faculty at the University of Guelph in Ontario, Canada, showed that a completely smoke-free campus had less support among students in comparison to other policy options, such as those that promote smoking cessation resources or allocate specific smoking areas ${ }^{19}$.

\section{Smoking status}

Among the many factors that may affect attitudes and behaviors towards smoke-free campus policies, smoking status, peer support, smoke exposure, gender, and perceived smoking prevalence, have been found to be significant ${ }^{18,21-23}$. In addition, it has been shown that there are significant differences in the levels of support for smoke-free policies between non-smokers and smokers among both students and faculty ${ }^{18,20}$. One study reported that approximately $80 \%$ of students and staff at Pacific Northwest University who never smoked were in favor of smoke-free policies ${ }^{18}$. In contrast, less than $20 \%$ of smokers were found to be in favor of the same policies ${ }^{18}$. Studies have also found that while former smokers are more supportive of smoke-free policies than current smokers, both groups strongly oppose these policies ${ }^{18,22}$. These findings correlate with those found by Braverman et al. ${ }^{21}$ and Ickes et al..$^{23}$, which showed that former and current tobacco users were in opposition to tobaccofree policies, and subsequently violated them more often. Studies show that the primary reason for former and current smokers' opposition to smoke-free or tobacco-free policies is their belief in an individual's freedom of choice ${ }^{10,17}$. Former smokers, in particular, may be more sympathetic towards the needs of smokers addicted to nicotine than those who have never smoked, perhaps explaining former smokers' increased opposition to such policies ${ }^{21}$. However, this is an area that is lacking in the literature and further studies are needed to understand why former smokers are more likely than never smokers to oppose smokefree or tobacco-free policies ${ }^{21}$. Seitz and Strack ${ }^{10}$ also showed that individual personality traits and beliefs could lead some students to oppose tobacco-free policies. Furthermore, addiction to nicotine and stress are factors suggested to have led some American students to protest against tobacco-free policies adopted by their universities ${ }^{10}$.

Although several studies show that a majority of students and faculty support smoke-free policies, both groups overestimate the number of smokers on campus $^{18,24}$. This may explain the positive attitudes these groups have towards smoke-free policies ${ }^{18,24}$. These positive attitudes were similar to those of students on a university campus near the US/ Mexican border that adopted a tobacco-free policy ${ }^{20}$. This suggests that if students and faculty have a more accurate perception of the number of smokers on campus, they may be less likely to support these policies.

\section{Secondhand smoke exposure}

Exposure to secondhand smoking is another important predictor of smoke-free or tobacco-free policy support ${ }^{10,18}$. Studies have shown that secondhand smoke exposure near campus boundaries and building entrances elucidates support for smoke-free policies among students, staff and faculty ${ }^{18,21}$. Contrarily, a study conducted on a large south-eastern campus in the US that enacted tobacco-free policies found that lower exposures to secondhand smoke fostered positive attitudes among students ${ }^{23}$. The same study demonstrated that although many students believed tobacco-free policies were effective at decreasing secondhand smoke exposure, graduate students believed in the effectiveness of such policies more than undergraduate students ${ }^{23}$. Mamudu et al. ${ }^{25}$ noted that knowledge of the harmful effects of secondhand smoke exposure was related to individuals having 
positive attitudes towards tobacco-free policies.

\section{Sociodemographics}

Sociodemographic factors have been found to play a major role in shaping attitudes and behaviors towards smoke-free and tobacco-free policies ${ }^{18,21,23}$. Several studies have shown that female students, staff and faculty are more likely to support smokefree and tobacco-free policies in comparison to their male counterparts ${ }^{18,21-23}$. Similarly, international students were found to frequently have more positive attitudes towards smoke-free and tobaccofree policies ${ }^{18,21,23}$. Sociodemographic factors such as being part of a sorority and living on campus were associated with negative attitudes towards these policies ${ }^{18,21,23}$. Braverman et al. ${ }^{18}$ and Hall et al. ${ }^{22}$ found that increased age is associated with increased levels of support for smoke-free and tobacco-free policies from staff members, as in most cases they have had more experience with smoking cessation. In addition, factors such as holding conservative political ideologies, having a family member who smokes, and being exposed to promotional materials created by the tobacco industry were associated with one having negative attitudes towards a tobacco-free policy on an American university campus ${ }^{25}$.

\section{Limitations}

This review had several limitations. Firstly, we included articles published in the English language only. As a result, relevant information or findings published in articles in other languages may have been inadvertently excluded from the review. Furthermore, our review included the analysis of articles published in peer-reviewed journals only. Therefore, information pertinent to the attitudes and behaviors of students, staff and faculty towards tobacco-free campus policies that have been published in academic reports, whitepapers, and dissertations was not included as part of this review. Finally, studies that examined the attitudes and behaviors of the campus community towards e-cigarette and/or tobacco chewing bans alone were excluded. While this constitutes a limitation of the present review, it also provides an opportunity for future research to investigate the nature of vaping and/or tobacco chewing bans on post-secondary campuses.

\section{CONCLUSIONS}

This literature review found that social norms, smoking status, secondhand smoke exposure, and demographics can influence an individual's support for, or opposition to, smoke-free and tobacco-free policies on North American campuses. Despite some of the studies examined having limitations due to crosssectional study design and lack of generalizability, this review provides timely information that educational institutions should consider when planning to adopt smoke-free and tobacco-free campus policies. We believe the momentum to move towards $100 \%$ smokefree or tobacco-free campuses is established, and support any campus taking that bold step. While there may be barriers and challenges unique to University campuses, they are not insurmountable. University campuses going smoke-free or tobacco-free are encouraged to share lessons and celebrate successes.

\section{REFERENCES}

1. Statistics Canada. The 10 leading causes of death, 2011. https://www150.statcan.gc.ca/n1/pub/82625-x/2014001/article/11896-eng.htm. Updated May 17, 2018. Accessed July 5, 2020.

2. Statistics Canada. Canadian Community Health Survey, 2014. https://www150.statcan.gc.ca/n1/dailyquotidien/150617/dq150617b-eng.htm. Updated June 25, 2015. Accessed July 5, 2020.

3. Adlaf EM, Gliksman L, Newton-taylor B. Cigarette Use Among Canadian Undergraduates. Can J Public Heal. 2001;94(1):22-24. doi:10.1007/bf03405046

4. Cairney J, Lawrance KA. Smoking on campus: An examination of smoking behaviours among postsecondary students in Canada. Can J Public Heal. 2002;93(4):313-316. doi:10.1007/bf03405024

5. Finnie R, Childs S, Wismer A. Access To PostSecondary Education Among Under-Represented And Minority Groups: Measuring The Gaps, Assessing The Causes. Education Policy Research Initiative Working Paper no. 2011-01. Ottawa, ON: University of Ottawa; 2011. https://pdfs.semanticscholar. org/41cc/d9ab5733e69a2da6dac4dae7805b310cbf1d. pdf?_ga $=2.255984706 .892196371 .1595498006$ 1739583808.1589524211. Accessed July 5, 2020.

6. Statistics Canada. Full-time teaching staff at Canadian universities, by rank and sex. http://www.statcan.gc.ca/ tables-tableaux/sum-som/101/cst01/educ68a-eng.htm. Published 2017. Accessed April 6, 2018.

7. Baillie L, Callaghan D, Smith M, et al. A review of undergraduate university tobacco control policy process in Canada. Health Educ Res. 2009;24(6):922-929. doi:10.1093/her/cyp026 
8. Hammond D, Tremblay I, Chaiton M, Lessard E, Callard C. Tobacco on campus: Industry marketing and tobacco control policy among post-secondary institutions in Canada. Tob Control. 2005;14(2):136-140. doi:10.1136/tc.2004.009753

9. Cohen JE, Ashley MJ, Ferrence R, Brewster JM, Goldstein AO. Institutional addiction to tobacco. Tob Control. 1999;8(1):70-74. doi:10.1136/TC.8.1.70

10. Seitz MC, Strack WR. Protest of tobacco-free policies on college campuses: a historical analysis. Health Educ. 2014;114(5):331-346. doi:10.1108/HE-09-2013-0046

11. Shields M. Smoking bans: influence on smoking prevalence. Heal reports. 2007;18(3):9-24. PMID:17892249.

12. Statistics Canada. Smokers, by age group. https://www150. statcan.gc.ca/t1/tbl1/en/tv.action?pid=1310009610. Accessed July 5, 2020.

13. Lechner WV, Meier E, Miller MB, Wiener JL, Fils-Aime $\mathrm{Y}$. Changes in smoking prevalence, attitudes, and beliefs over 4 years following a campus-wide anti-tobacco intervention. J Am Coll Heal. 2012;60(7):505-511. doi:10.1080/07448481.2012.681816

14. Lupton JR, Townsend JL. A systematic review and metaanalysis of the acceptability and effectiveness of university smoke-free policies. J Am Coll Heal. 2015;63(4):238247. doi:10.1080/07448481.2015.1015029

15. Canadian Cancer Society. University and College 100\% Smoke-Free Campuses in Canada: National Status Report. https://www.cancer.ca/ /media/cancer.ca/CW/get $\% 20$ involved/take\%20action/University-college-100-percentsmoke-free-campus-national-report-2020-03-11(1). pdf?la=en. Published March 11, 2020. Accessed July 5, 2020.

16. Record RA. Tobacco-Free Policy Compliance Behaviors among College Students: A Theory of Planned Behavior Perspective. J Health Commun. 2017;22(7):562-567. doi:10.1080/10810730.2017.1318984

17. Procter-Scherdtel A, Collins D. Social norms and smoking bans on campus: Interactions in the Canadian university context. Health Educ Res. 2013;28(1):101112. doi:10.1093/her/cys075

18. Braverman MT, Hoogesteger LA, Johnson JA. Predictors of support among students, faculty and staff for a smokefree university campus. Prev Med. 2015;71:114-120. doi:10.1016/j.ypmed.2014.12.018

19. Wallar LE, Croteau S, Estill A, Robson L, Papadopoulos A. Analyzing Exposure, Use, and Policies Related to Tobacco Use on Campus for the Development of Comprehensive Tobacco Policies at Canadian Post-secondary Institutions. J Community Health. 2013;38(6):1081-1089. doi:10.1007/s10900-013-9717-6

20. Cooper TV, Cabriales JA, Hernandez N, Law J. A baseline assessment of attitudes toward tobacco free campus policies in a U.S./México border university. Addict Behav. 2016;60:223-227. doi:10.1016/j.addbeh.2016.04.023
21. Braverman MT, Hoogesteger LA, Johnson JA, Aarø LE. Supportive of a smoke-free campus but opposed to a $100 \%$ tobacco-free campus: Identification of predictors among university students, faculty, and staff. Prev Med. 2017;94:20-26. doi:10.1016/J.YPMED.2016.10.021

22. Hall ME, Williams RD, Hunt B. Assessment of Attitudes Regarding Tobacco-Free Campus Policy and Secondhand Smoke Exposure Among College Students, Faculty, and Staff. Am J Heal Educ. 2015;46(1):48-57. doi:10.1080/19325037.2014.945671

23. Ickes MJ, Rayens MK, Wiggins A, Hahn EJ. Students' Beliefs About and Perceived Effectiveness of a Tobacco-Free Campus Policy. Policy, Polit Nurs Pract. 2017;18(1):17-25. doi:10.1177/1527154417700633

24. Fallin A, Roditis M, Glantz SA. Association of campus tobacco policies with secondhand smoke exposure, intention to smoke on campus, and attitudes about outdoor smoking restrictions. Am J Public Health. 2015;105(6):1098-1100. doi:10.2105/AJPH.2014.302251

25. Mamudu HM, Veeranki SP, Kioko DM, Boghozian RK, Littleton MA. Exploring Support for 100\% College Tobacco-Free Policies and Tobacco-Free Campuses Among College Tobacco Users. J Public Heal Manag Pract. 2016;22(1):29-39. doi:10.1097/PHH.0000000000000262

\section{CONFLICTS OF INTEREST}

The authors have completed and submitted the ICMJE Form for Disclosure of Potential Conflicts of Interest and none was reported.

\section{FUNDING}

There was no source of funding for this research.

PROVENANCE AND PEER REVIEW

Not commissioned; externally peer reviewed. 